\title{
Association between Outdoor Ambient Illuminance and Elderly People's Moods in a Care Home
}

\author{
By Ashikur Rahman Joarder * \\ Andrew DF Price ${ }^{\dagger}$
}

\begin{abstract}
Daylight has potential to stimulate individual's sensations and feelings. Older people who live in care homes should have some sense of outdoor daylight that might influence their moods. This paper describes a pilot study that investigates the association between the outdoor ambient illuminance and elderly people's mood changes in a care home environment while controlling other contributory factors, such as outdoor temperature, occupant age, gender and medical conditions (e.g. dementia and blindness). Real world field data was collected from an existing care home. Environmental data (outdoor illuminance and temperature) was collected by installing outdoor data loggers on the roof top of the care home. Demographic and physiological information of the occupants were collected from care home records. Care home staff rated occupants' moods on a Likert-type scale composed of three quantifiable response modes: numerical rating scale (NRS), visual analogue scale (VAS) and faces rating scale (FRS). Ordered logit (OLOGIT) model, suitable to develop correlation between ordinal dependent variables (i.e. mood) and continuous data (i.e. illuminance) are used. The analysis shows, assuming all other explanatory variables remain constant, the probability of a better mood increases with the increase of outdoor illuminance ( $p$-value=0.022). However, in a very hot/cold day the probability of a better mood could be decreased under the same outdoor daylight level.
\end{abstract}

Keywords: elderly people, Likert-type scale, mood, ordered response model, outdoor illuminance

\section{Introduction}

Light effects on individuals: physically (Lim et al. 2006, Whyte and Thakker 2005, Holick 2004), physiologically (Joarder and Price 2013, Choi et al. 2012, Joarder et al. 2010, Walch et al. 2005), and psychologically (Ljubičić et al. 2007, Kecskes et al. 2003, Oren et al. 2002, Benedetti et al. 2001, Beauchemin and Hays 1996). The psychological effects of light can be observed under two incidents: longer-term effects and short term effects (McCloughan et al. 1999). The longerterm effects of light involve complex biological interactions that result a couple of syndrome, such as, depression and seasonal affective disorder (SAD). As short term effects, illuminance and correlated colour temperature (CCT) of light create stimulation to individuals' sensations that might affect individuals' moods. In this research, longer term effects has been considered as the effects that develop and continue over days and seasons; short term effects are temporary with a duration of equal or less than a day (24 hours) and should change over consecutive days. Change of mood has been assumed as one of the potential short term effects of ambient outdoor illuminance. Mood has been defined as the core feelings of an

\footnotetext{
* Associate Professor, Department of Architecture, Bangladesh University of Engineering and Technology (BUET), Bangladesh.

${ }^{\dagger}$ Professor, School of Civil and Building Engineering, Loughborough University, UK.
} 
individual's subjective state of mind at any given moment due to many unknown reasons (Russell and Snodgrass 1987). Many researchers distinguish mood from emotion as emotion may have identifiable causes (McCloughan et al. 1999).

The longer term effects of seasonal change of light on individual's behaviour and mood, i.e. SAD is one of the most developed researched subjects among the psychological effects of natural light (Edwards and Torcellini 2002, Kasper et al. 1989, Rosenthal et al. 1984). The seasonal pattern suggests that natural illuminance is an important factor to influence SAD and mood disorder (Dumont and Beaulieu 2007). However, the short term effects of light (i.e., impact of light on mood and behaviour at a particular moment) are still a matter of dispute within the scientific research community. At an empirical level, the existing literature contains a mix of contradictory evidence of short term effects of light on individuals' moods (McCloughan et al. 1999). Some researchers reported that positive moods are associated with lower illuminance (Baron et al. 1992, Nelson et al. 1984), some argued this occurring at higher illuminances (Boyce and Cuttle 1990, Belcher and Kluczny 1987), while some others found no correlation between moods and illuminance (Kuller and Wetterberg 1993). Most of these assessments are conducted under artificial lighting setup in laboratories or clinics, and few empirical research exist on the short term effect of natural illuminance on moods.

It is expected that the impact of natural illuminance (i.e. daylight) on mood will be different from the impact of artificial illuminance, as the experience of natural illuminance in the real world is totally different from the conditions in laboratory studies. For example, in an artificial setup illuminance are generally kept constant for the entire length of the experiment and monochromatic lights are mostly used. Daylight is polychromatic and the illuminance changes rapidly over the day. It is expected that the moods under a higher constant illuminance will be different from the moods under the changing levels of illuminance ranges from very high to very low in a 24 hour sequence. The short term effects of varying levels of outdoor illuminance, on individuals' moods are still largely unknown (Dumont and Beaulieu 2007). This research investigates, in addition to the established long term effects of light on individual's mood and behaviour (i.e. $\mathrm{SAD}$ ), if there is any short term effect of natural illuminance on individual's mood. As diurnal pattern of daylight involves a couple of hours with no daylight at night (i.e. eight to 16 hours for UK climate) (Joarder 2011), this allows to distinguish the mood of a particular day from consecutive days.

Higher intensity of light is needed to be incident on individuals' eye retinas to start biological stimulation inside the human body (Lockley and Gooley 2006). Apart from direct contact, a sense of outdoor illuminance might have some kind of short term effect on individual's moods when individuals are not exposed to direct sunlight and stay indoors. This research investigates if there is any short term effect of the sense of outdoor illuminance on the individuals who stay indoors. Older people in care home, in this regard, is a sensible choice as the sample for this study, since they stay most of their time in indoors (Littlefair 2010), but should have a sense of ambient outdoor climatic condition (e.g. daylight and temperature) through windows and openings, that might influence their moods. 
The primary aim of this study is to explore the association between outdoor ambient illuminance and elderly people's moods in a care home. The relationship between outdoor illuminance and elderly people mood may not be straightforward, since a number of external factors and individuals' physical, physiological and psychological conditions might affect the mood. Therefore, in addition to outdoor ambient illuminance, other contributory factors such as outdoor temperature, occupant age, gender, dementia type (e.g. mild, moderate, vascular and advanced) and psychophysical conditions (e.g. depression, blindness, frailness and disabilities), have been considered in this research. Statistical models suitable for both continuous data and ordered dependent variable (mood), such as very sad, sad, neutral, happy and very happy, are used. The paper is organized as follows. The next section provides a discussion of the methods, applied in this research, with description of the statistical models used in the study. This is followed by a description of the data used in the analysis. The estimation results along with a discussion on the findings are then presented. The paper ends with limitations, conclusions, and future research directions.

\section{Methodology}

\section{Care Home and Participants}

In order to examine the association between the change of elderly people's moods with the change of outdoor, ambient natural illuminance under a care home environment, the Alexandra House, located at Leicester, UK (Figure 1) was chosen as a case study.

Figure 1. Alexandra House (17 Bed Care Home), Leicester, UK

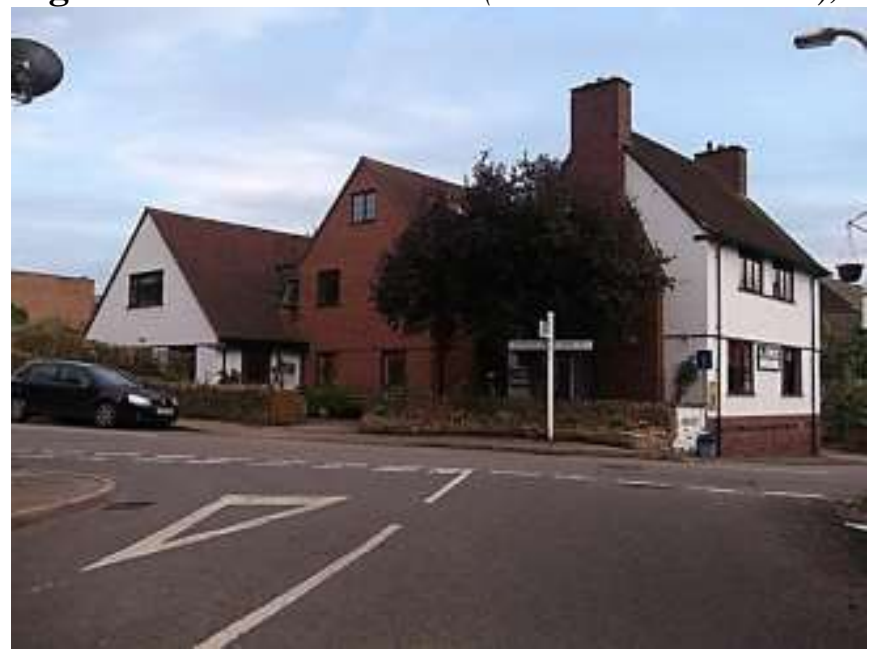

Leicester is the largest and most populated city in the East Midlands and the fifteenth largest in the UK with a population around 280,000 (in 2007) (Lomas and Kane 2013). Found on the River Soar and bordering the National Forest in 
Leicestershire, Leicester is one of the most ethnically diverse cities in the United Kingdom (after London). The city's climate is maritime with mild winters and cool summers, classified as Cfb by the Köppen-Geiger system (CDO 2012). There is a great deal of rainfall in Leicester, even in the driest month. The mean annual rainfall ranges from a minimum of about $630 \mathrm{~mm}$ to more than $700 \mathrm{~mm}$ (Cheney 2004). Maximum temperatures in summer are around $25.8^{\circ} \mathrm{C}$ (Lomas and Kane 2013), and the minimum temperatures in winter are around $0^{\circ} \mathrm{C}$. The average annual temperature is $9.7^{\circ} \mathrm{C}$ in Leicester (CDO 2012).

Alexandra House is a private residential care home with 17 en-suite bedrooms. The elderly people, who stayed in the care home during 25 January 2012 to 27 April 2012, were taken as the sample for this study. The objectives of the research were told to the owners of the care home and researchers took approval prior to start the survey. All 17 residents and 14 staff of the care home agreed to participate in the study by signing the Informed Consent Forms. This research ensures compliance with the Data Protection Act 1998 and was checked by an Ethical Advisory Committee. Majority of the participated elderly people were female $(88 \%)$, white $(100 \%)$ with an average age of 90 years $(\mathrm{SD}=4.774)$. It is important to mention that due to participants' higher ages, in most of the time of the day they tend to stay inside the care home in lounges with large glass windows visually exposed to outdoor illumination with a sense of state of outdoor temperature.

\section{Data Collection}

Climatic data were collected by installing two outdoor data loggers (UA002-64, Pendant Logger Temp/Light, 64k memory) at the roof top of the care home that records ambient horizontal exterior illuminance (HEI) in lux and temperature in ${ }^{\circ} \mathrm{C}$, with one hour and three hours intervals. The hourly climatic data were used in this study and cross checked with the three hours interval data obtained from the other logger. The instantaneous hourly climatic data were averaged for the 24 hours to identify the average illuminance and temperature level of a particular date.

To identify occupants' moods in the care home, a lens model design approach (Brunswik 1952, 1939, 1934) was followed. Lens model consider that individuals' judgments depend on their attention to, and weighting of the evidence (cues) available to them (Hirsh et al. 2011). To function the lens effectively, there must be some kind of dynamic activities and the judgements should be contextually determined, non-determinist and probabilistic in nature. The outcome of the staff judgments about occupants' moods in the care home can be expressed by using a quantifiable response mode (Hirsh et al. 2009), such as a numerical rating scale (NRS), visual analogue scale (VAS), verbal descriptor scale (VDS), and faces rating scale (FRS). It is practical to combine two or more scales (Fadaizadeh et al. 2009), because some individuals seem to have difficulties in interpreting NRS, and some lack the ability of abstract thinking required for assessment (Ferrell et al. 1995), or some find some scales confusing (Kremer et al. 1981, Revill et al. 1976). In this study a Likert-type scale was used that is composed of three quantifiable 
response modes (Figure 2): NRS consisting of five numbers linked with FRS with five facial expressions of moods and VDS from very sad (scored 1) to very happy (scored 5). The concept of lens model approach was used to form judgments on the mood of the residents in the care home by the duty stuff by capturing some information about the behavior, activity and expression of the occupants, visually.

Figure 2. Likert-Type Scale Used to Rate Elderly People's Moods

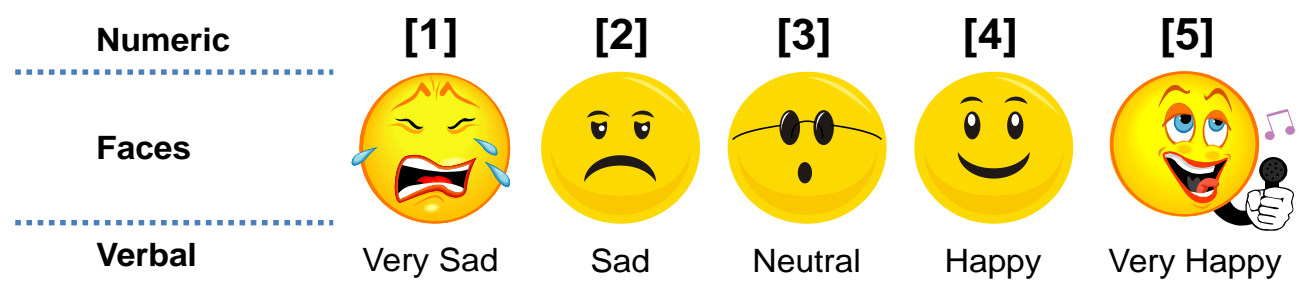

The care home staff were briefed about how to record the moods without disclosing the objective of the study. In fact, this research is designed for 12 months with a couple of objectives to develop correlation between several factors that might affect the mood and wellbeing of elderly people in care home and to recommend environmental standards. Identification of the association between outdoor illuminance and elderly people's moods is one of the primary objectives for first three months pilot study that has been presented in this paper. There were 14 care staff employed in the care home. Majority of the staff were female (100\%), white (93\%), with an average age of approximately 35.5 years ( $\mathrm{SD}=7.8)$. Among 14 care staff: one have Diploma in Health and Social Care L2, and five are completing; four have completed Health and Safety Executive (HSE) in First Aid at Work; four have completed National Vocational Qualification (NVQL2/L3) in Health and Social Care; two have NVQL2 in Food Preparation and Production; and one have NVQL2 in Customer Services.

Staff were requested not to spend much time to make their judgments, but apply their quick intuitive feelings on occupant's moods, considering the previous six to eight hours activities and facial expressions of the occupants, in which a very bad mood (i.e. crying loudly) can be coded as 1 , a mood neither crying nor normal can be coded as 2 (i.e. sad face), a normal mood without any strong emotion can be coded as 3 (i.e. poker face), a mood between normal to very happy can be coded as 4 (i.e. smiling face) and a very happy mood (i.e. singing and/or dancing) can be coded as 5 (Figure 2). The senior care stuff on duty recorded the occupants' moods with discussion with other duty staff three times in a day at 07:30 am, 02:00 pm and 10:00 pm, before shifting their duty to next staff team. In order to take into account about the overall mood of the day, the three numbers that represent the moods of a particular occupant at three times in a day were averaged. In case of fractioned average numbers, the numbers were turned to the whole numbers (i.e. 1, 2, 3, 4 and 5) to represent the overall mood of the occupant on the NRS (Figure 2). The information about other contributory factors that might affect the occupant's moods, such as occupant age, gender, dementia type (e.g. early, moderate, vascular and 
advanced) and psychophysical conditions (e.g. depression, blindness, frailness and disabilities), were collected from care home records. Table 1 shows summary statistics of the variables that was primarily considered to develop ordered logit models with different set of explanatory variables.

Table 1. Summary Statistics of the Variables that was Primarily Considered to Develop Different OLOGIT Models

\begin{tabular}{|c|c|c|c|c|}
\hline Quantitative Variables & Min & $\operatorname{Max}$ & Mean & Standard Deviation \\
\hline $\begin{array}{l}\text { Average ambient outdoor } \\
\text { illuminance of the day (lux) }\end{array}$ & 2311 & 46655 & 184490.27 & 11590.992 \\
\hline $\begin{array}{l}\text { Average ambient outdoor } \\
\text { temperature of the day }\left({ }^{\circ} \mathrm{C}\right)\end{array}$ & -4 & 14 & 7.17 & 3.982 \\
\hline Age (year) & 82 & 97 & 89.86 & 4.776 \\
\hline $\begin{array}{l}\text { Categorical or dummy } \\
\text { variables }\end{array}$ & \multicolumn{4}{|c|}{ Description } \\
\hline Mood & \multicolumn{4}{|c|}{$\begin{array}{l}1=\text { very bad }(\operatorname{count}=18) ; 2=\operatorname{bad}(\operatorname{count}=113) ; \\
3=\text { neutral }(\operatorname{count}=677) ; 4=\operatorname{good}(\operatorname{count}=310) ; \\
5=\text { very } \operatorname{good}(\operatorname{count}=12)\end{array}$} \\
\hline Gender & \multicolumn{4}{|c|}{$\begin{array}{l}1=\text { male }(\text { count }=187) \\
0=\text { otherwise }(\text { count }=1399)\end{array}$} \\
\hline Frailness & \multicolumn{4}{|c|}{$\begin{array}{l}1=\text { frail elderly people }(\text { count }=92) \\
0=\text { otherwise }(\text { count }=1494)\end{array}$} \\
\hline Depression & \multicolumn{4}{|c|}{$\begin{array}{l}1=\text { manic depressed }(\text { count }=94) \\
0=\text { otherwise }(\text { count }=1492)\end{array}$} \\
\hline Blindness & \multicolumn{4}{|c|}{$\begin{array}{l}1=\text { registered blind }(\text { count }=94) \\
0=\text { otherwise }(\text { count }=1492)\end{array}$} \\
\hline Physical Disability & \multicolumn{4}{|c|}{$\begin{array}{l}1=\text { physically disable people }(\text { count }=93) ; \\
0=\text { otherwise }(\text { count }=1493)\end{array}$} \\
\hline Early Dementia & \multicolumn{4}{|c|}{$\begin{array}{l}1=\text { early dementia }(\text { count }=468) \\
0=\text { otherwise }(\text { count }=1118)\end{array}$} \\
\hline Moderate Dementia & \multicolumn{4}{|c|}{$\begin{array}{l}1=\text { moderate dementia }(\text { count }=280) ; \\
0=\text { otherwise }(\text { count }=1306)\end{array}$} \\
\hline Vascular Dementia & \multicolumn{4}{|c|}{$\begin{array}{l}1=\text { vascular dementia }(\text { count }=559) ; \\
0=\text { otherwise }(\text { count }=1027)\end{array}$} \\
\hline Advanced Dementia & \multicolumn{4}{|c|}{$\begin{array}{l}1=\text { advanced dementia }(\text { count }=92) \\
0=\text { otherwise }(\text { count }=1494)\end{array}$} \\
\hline
\end{tabular}

\section{Statistical Model}

In this study the variable of interest (i.e. elderly people's moods) is ordinal. That is, elderly people's moods (dependent variable) can be ordered in the nature from very sad to very happy on a Likert-type scale by ranking from 1 to 5, but the real distance between categories is unknown. When such an ordinal variable appears on the left-hand side of a statistical model, the suitable model to deal with this ordered categorical variable is ordered logit (OLOGIT) model (Gujarati 2003, Greene 2000, Long 1997, Clogg and Shihadeh 1994, McCullagh and Nelder 1989). Other approaches, such as ordinary least squares (OLS) estimation is not appropriate for an ordinal dependent variable, and suffers many shortcomings 
(Long 1997). To investigate the impact of outdoor ambient illuminance on the elderly people's moods, the concept of "ordered" model is chosen, and OLOGIT models have been developed in this research. Assuming that the elderly people's mood is an ordered discrete variable with $j$ categories, that is very sad (1), sad (2), neutral (3), happy (4), and very happy (5), an OLOGIT model (in terms of probability) can be written as (Norušis 2010):

$$
\begin{aligned}
\operatorname{prob}(\operatorname{mood} & \leq j)=\frac{1}{1+\exp \left[-\left\{\alpha_{j}-\left(\beta_{1} x_{1 i}+\beta_{2} x_{2 i}+\ldots+\beta_{p} x_{p i}\right)\right\}\right]} \\
& =\frac{1}{1+\exp \left(\beta_{1} x_{1 i}+\beta_{2} x_{2 i}+\ldots+\beta_{p} x_{p i}-\alpha_{j}\right)}
\end{aligned}
$$

where $j$ goes from 1 to the number of categories minus 1 (i.e. 4 for 5 moods). Each prob has its own $\alpha_{j}$ term, called the threshold value (or cut points), but the same coefficients $\beta_{1}$ to $\beta_{p}$ relating the $p$ explanatory variables to the variables of interest (mood). The parameters of the model ( $\beta$ 's) and the threshold values $\left(\alpha_{j}\right.$ 's) are estimated by the method of maximum likelihood (Long 1997) usually computed by statistical software packages (e.g. SPSS Ordinal Regression procedure, or PLUM - Polytomous Universal Model).

In ordinal logistic regression, the event of interest is observing a particular score or less. The events in an ordinal logistic model are not individual scores but cumulative scores. The estimated probabilities of the individual scores can be calculated from the estimated cumulative probabilities by subtraction, using the formula as (Norušis 2010):

$$
\operatorname{prob}(\operatorname{mood}=j)=\operatorname{prob}(\operatorname{mood} \leq j)-\operatorname{prob}(\operatorname{mood}<j)
$$

The probability for $(\operatorname{mood}=1)$ does not require any modifications to Equation 1. For the remaining four moods, the differences between cumulative probabilities can be calculated as (Norušis 2010):

$\operatorname{prob}(\operatorname{mood}=2)=\operatorname{prob}(\operatorname{mood}=1,2)-\operatorname{prob}(\operatorname{mood}=1)$

$\operatorname{prob}(\operatorname{mood}=3)=\operatorname{prob}(\operatorname{mood}=1,2,3)-\operatorname{prob}(\operatorname{mood}=1,2)$

$\operatorname{prob}(\operatorname{mood}=4)=\operatorname{prob}(\operatorname{mood}=1,2,3,4)-\operatorname{prob}(\operatorname{mood}=1,2,3)$

$\operatorname{prob}(\operatorname{mood}=5)=1-\operatorname{prob}(\operatorname{mood}=1,2,3,4)$

The probability for last category $(\operatorname{mood}=5)$ does not have an odds associated with it since the probability of mood up to, and including the last score is 1 .

\section{Variables Selection}

At the beginning, Pearson correlations among the primary selected continuous, explanatory variables were analysed to determine the multicolinearity between primary selected explanatory variables that may bias the standard error, generate wrong sign and implausible magnitudes in the coefficients (Chin and Quddus 2003). There was no high correlation between the explanatory variables 
used in the model (all correlation coefficients were between -0.007 and +0.523 ). The set of uncorrelated explanatory variables was used to estimate OLOGIT models with different set of explanatory variables.

Table 2 compares two PLUM - Ordinal Regression models generated by SPSS: a primary model with all 12 explanatory variables listed earlier in Table 1 ; and a second model with four explanatory variables identified by a stepwise selection method employing log-likelihood ratio (LR) tests. Table 2 shows that both the models are capable to provide adequate predictions compared to the intercept only (null model); therefore, outperforms the null model (Loglikelihood Chi-Square: $\mathrm{p}<0.001$ ). The variables depression, physical disability, vascular dementia and early dementia are not significant at a level of $10 \%$ in primary model; therefore, should be dropped from the model.

Table 2. Model Estimation Results for the Primary and the Second Models

\begin{tabular}{|c|c|c|c|}
\hline & $\begin{array}{c}\text { Primary } \\
\text { model } \\
\text { estimate }\end{array}$ & $\begin{array}{c}\text { Second } \\
\text { model } \\
\text { estimate }\end{array}$ \\
\hline \multirow{12}{*}{$\begin{array}{l}\text { Factors } \\
\text { affecting the } \\
\text { ordinal } \\
\text { categorical } \\
\text { choice }(X)\end{array}$} & Average illuminance of the day & $1.726 \times 10^{-5 b}$ & $1.740 \times 10^{-5 b}$ \\
\hline & Average temperature of the day & $-0.033^{b}$ & $-0.035^{b}$ \\
\hline & Age & $0.055^{\mathrm{a}}$ & \\
\hline & Gender & $-0.410^{\mathrm{c}}$ & \\
\hline & Frailness & $-2.197^{\mathrm{a}}$ & $-1.306^{\mathrm{a}}$ \\
\hline & Depression & 0.079 & \\
\hline & Blindness & $-1.787^{\mathrm{a}}$ & \\
\hline & Physical Disability & -0.078 & \\
\hline & Early Dementia & 0.152 & \\
\hline & Moderate Dementia & $-0.502^{b}$ & $-0.517^{\mathrm{a}}$ \\
\hline & Vascular Dementia & 0.326 & \\
\hline & Advanced Dementia & $-1.623^{a}$ & \\
\hline \multirow[t]{11}{*}{ Statistics } & Threshold $[\operatorname{mood}=1]$ & 0.448 & $-4.284^{\mathrm{a}}$ \\
\hline & Threshold $[\operatorname{mood}=2]$ & $2.598^{\mathrm{c}}$ & $-2.170^{a}$ \\
\hline & Threshold [mood $=3]$ & $5.762^{\mathrm{a}}$ & $0.863^{\mathrm{a}}$ \\
\hline & Threshold [mood $=4]$ & $9.447^{\mathrm{a}}$ & $4.500^{\mathrm{a}}$ \\
\hline & Observations & 1130 & 1130 \\
\hline & Degree of freedom & 12 & 4 \\
\hline & Log-likelihood Chi-Square & $91.209^{\mathrm{a}}$ & $34.702^{\mathrm{a}}$ \\
\hline & Test of Parallel Lines & $68.166^{\mathrm{a}}$ & 17.325 \\
\hline & Cox and Snell Pseudo R-Square & 0.078 & 0.030 \\
\hline & Nagelkerke Pseudo R-Square & 0.090 & 0.035 \\
\hline & McFadden Pseudo R-Square & 0.040 & 0.015 \\
\hline
\end{tabular}

One of the important assumptions associated with an OLOGIT regression is proportional odds assumption or the parallel regression/lines assumption (Long 1997) that considers the relationship between each pair of outcome groups is the same. If the proportional odds assumption is not valid, different models are needed 
to describe the relationship between each pair of outcome groups. It is essential to test the proportional odds assumption after estimating an OLOGIT model (Quddus et al. 2010). Although, the proportion of variation being explained by the primary model is higher (Nagelkerke Pseudo R-Square $=0.09$ ) compared to the second model (Nagelkerke Pseudo R-Square=0.035); the test of parallel lines shows that the proportional odds assumption is violated in the primary model as the p-value (sig) is lower than 0.05 (Chan 2005). In this case, one set of coefficients for all the categories is not appropriate and use of the OLOGIT model with all primary selected variables may lead to incomplete, incorrect, or misleading results. Since, the assumption of all categories having the same parameters is not reasonable for the primary model; consideration of multinomial regression (that ignores the ordinal nature in the categories) might be useful. Application of multinomial regression with 12 explanatory variables provides statistically insignificant pvalues for the estimates. The test of parallel lines for second model shows that the $\mathrm{p}$-value is higher than 0.05 ( $\mathrm{p}$-value $=0.138$ ), implies that separate parameters for each category would not be more appropriate for this second model with four explanatory variables, and thus this model might be suitable as an OLOGIT model. Inclusion of any significant variable from the primary model to the second model results decrease of $p$-value in parallel line test, without any significant increase in Pseudo R-Square. The estimates for the four statistically significant variables common between the two models are quite similar in most of the cases, in terms of signs and values (except frailness). The estimates for all four cut points become highly significant ( $\mathrm{p}$-value $<0.001$ ) for second model, whereas for the primary model only two cut points were highly significant ( $p$-value $<0.001$ ). Comparing the two models presented in Table 2, significant predictors determined for mood in this paper are outdoor illuminance, temperature, frailness and moderate dementia. It is expected that all four explanatory variables had an impact on the level of elderly people's moods in care home.

The threshold portion of Table 2 shows the constants/intercepts of the models. A positive relationship exists between outdoor illuminance and the ordinal outcome. This means that as outdoor illuminance increases, so does the probability of being in one of the higher mood categories. On the other hand, outdoor temperature has a negative relationship, means that a lower outdoor temperature is associated with the probability of a better mood. In practice, this is not true as occupants will feel uncomfortable under both very high and low temperature (e.g. minus value). Previous studies on thermal comfort in outdoor urban spaces for European Countries show that individuals feel neither warm nor cool over $10^{\circ} \mathrm{C}$ (up to $23^{\circ} \mathrm{C}$ ) (Nikolopoulou and Lykoudis 2006). In order to avoid the positive effect of lower outdoor temperature, instead of average outdoor temperature value the squared difference in average outdoor temperature from ten degree centigrade $\left(\left(10^{\circ} \mathrm{C} \text { - average temperature }\right)^{2}\right)$ was used for the final OLOGIT model which allowed better prediction. 


\section{Results and Discussion}

Table 3 shows the estimation of the parameters for final OLOGIT model. To describe the relationship between elderly people's moods and outdoor ambient illuminance, two environmental variables (ambient outdoor illuminance and squared difference in average outdoor temperature from $10^{\circ} \mathrm{C}$ ) and two physiological variables (frailness and moderate dementia) were found suitable for the final OLOGIT model. Two physiological variables were highly significant, i.e. $p$-value $<0.01$, outdoor illuminance was significant at a level of two percent and squared difference in average outdoor temperature from $10^{\circ} \mathrm{C}$ was significant at a level of 5\% in the final OLOGIT model. Assuming all other explanatory variables remain constant, the directions of the mood change as shown by the estimates in Table 3 are as following.

(a) Increasing outdoor ambient illuminance is associated with improved $\operatorname{mood}(\mathrm{p}=0.022)$.

(b) Increasing the squared difference in average outdoor temperature (from $\left.10^{\circ} \mathrm{C}\right)$ is associated with decreased $\operatorname{mood}(\mathrm{p}=0.049)$.

(c) Frail elderly people are more likely to have a decreased mood compared to others $(\mathrm{p}=<0.001)$.

(d) Older people with moderate dementia are more likely to have a decreased mood compared to others $(\mathrm{p}=0.002)$.

Table 3. Estimation of the Parameters (Final OLOGIT Model)

\begin{tabular}{|l|c|c|}
\hline & Estimate & p-value (sig) \\
\hline $\begin{array}{l}\text { Average ambient outdoor illuminance of } \\
\text { the day }\end{array}$ & $1.344 \times 10^{-5}$ & 0.022 \\
\hline $\begin{array}{l}\text { Squared difference in average outdoor } \\
\text { temperature from } 10^{\circ} \mathrm{C}\end{array}$ & -0.003 & 0.049 \\
\hline Frailness & -1.305 & $<0.001$ \\
\hline Moderate Dementia & -0.520 & 0.002 \\
\hline Threshold [mood =1] & -4.028 & $<0.001$ \\
\hline Threshold [mood = 2] & -1.914 & $<0.001$ \\
\hline Threshold [mood =3] & 1.118 & $<0.001$ \\
\hline Threshold [mood = 4] & 4.755 & $<0.001$ \\
\hline
\end{tabular}

Notes: Number of observations: 1130; Nagelkerke pseudo- ${ }^{2}$ : 0.034; chi-squared: 33.980 $(<0.001)$; parallel lines test: $16.990(0.150)$.

The collected data from the case care home suggest that higher value of outdoor ambient illuminance and lower value of the squared difference in average outdoor temperature from $10^{\circ} \mathrm{C}$ are associated with the probability of a better mood. Frail elderly people and people with moderate dementia had a lower probability to be in a higher mood categories compared to others. For logit link, taking the exponential of the estimates gives the odds ratios (OR). For example, the coefficient estimates of the final OLOGIT model suggest that while assuming the other explanatory variables in the model remain constant, 
for a one thousand lux increase in average outdoor ambient illuminance is associated with the odd of being in a higher level of mood being multiplied by $\exp \left(1.344 \times 10^{-2}\right)=1.0135$, i.e. an increase in the odd by $1.35 \%$. In case of temperature, for a one unit increase in the squared difference in average outdoor temperature from $10^{\circ} \mathrm{C}$ is associated with the odd of being in a lower level of mood being multiplied by exp $(0.003)=1.003$, i.e. a decrease in the odd by $0.3 \%$, given that all of the other variables in the model are remained constant. Using the estimated coefficients and cut points (Table 3), the OLOGIT equations can be written as following for the estimated cumulative mood probabilities (following Equation 1).

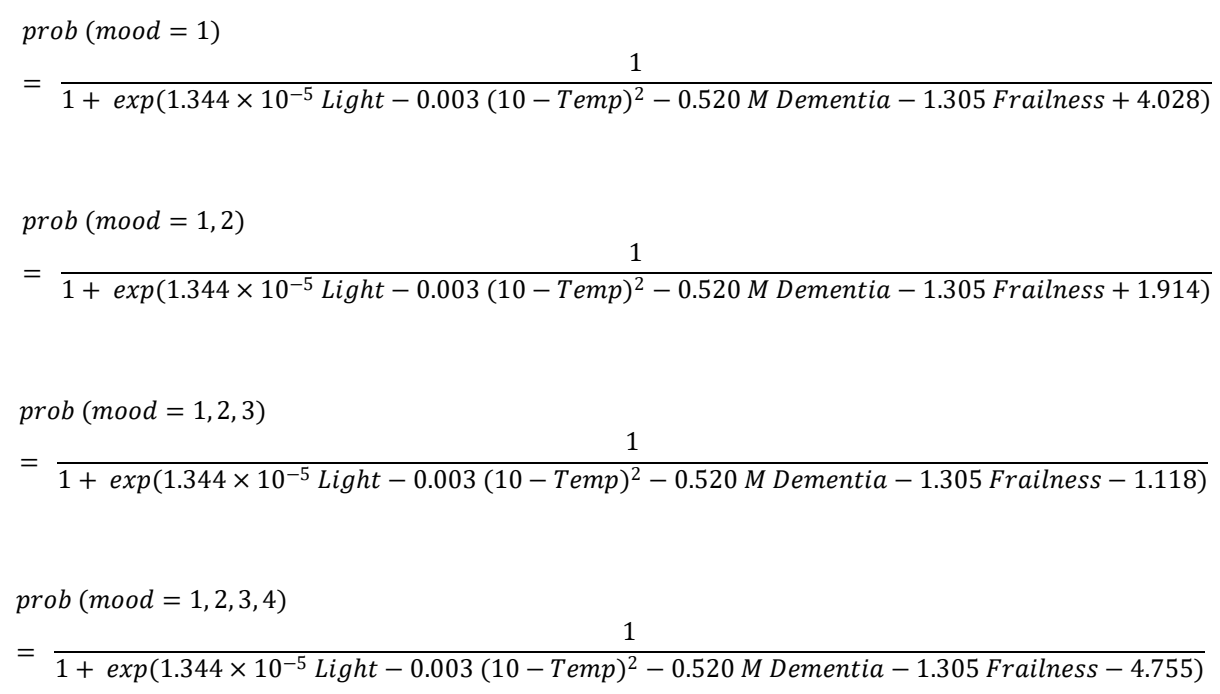

The probabilities of five different mood categories can be estimated by combined application of the Equations 3-10, under given conditions of outdoor illuminance, temperature, frailness and dementia. It is of interest to estimate the probability of a specific mood occurring, i.e., very bad, bad, neutral, good and very good, for given values of average outdoor illuminance and temperature levels. Figure 3 shows how the predicted probabilities of different categories of moods change with the change in the outdoor temperature values for a frail elderly people with moderate dementia, when the average outdoor illuminance level is fixed to 18,500 lux (average calculated from the collected three months outdoor illuminance data). Under 18,500 lux outdoor illuminance or lower, there is a little probability that the occupant will be in a good or very good mood. If the outdoor temperature increases to $24^{\circ} \mathrm{C}$ or higher, the occupants are more likely to be in a bad mood, while temperature higher than $37^{\circ} \mathrm{C}$ is associated with probability of a very bad mood, keeping the other circumstances constant.

Figure 4 presents the predicted probabilities of different mood categories for different outdoor illuminance for a non-frail elderly people with no dementia, when the average outdoor temperature is $7^{\circ} \mathrm{C}$ (average calculated from the collected three months outdoor temperature data). In a $7^{\circ} \mathrm{C}$ outdoor 
temperature, there is a high probability that the occupant will not be in a bad or very bad mood. If the average outdoor illuminance of the day increases to 80,000 lux or higher, the occupants are more likely to be in a good mood, while daily average outdoor illuminance higher than 350,000 lux is associated with the probability of a very good mood, keeping the other circumstances constant.

Figure 3. Predicted Probabilities of Different Mood Categories for Different Outdoor Temperature Values for a Frail Elderly People with Moderate Dementia Under 18,500 Lux Average Outdoor Illuminance

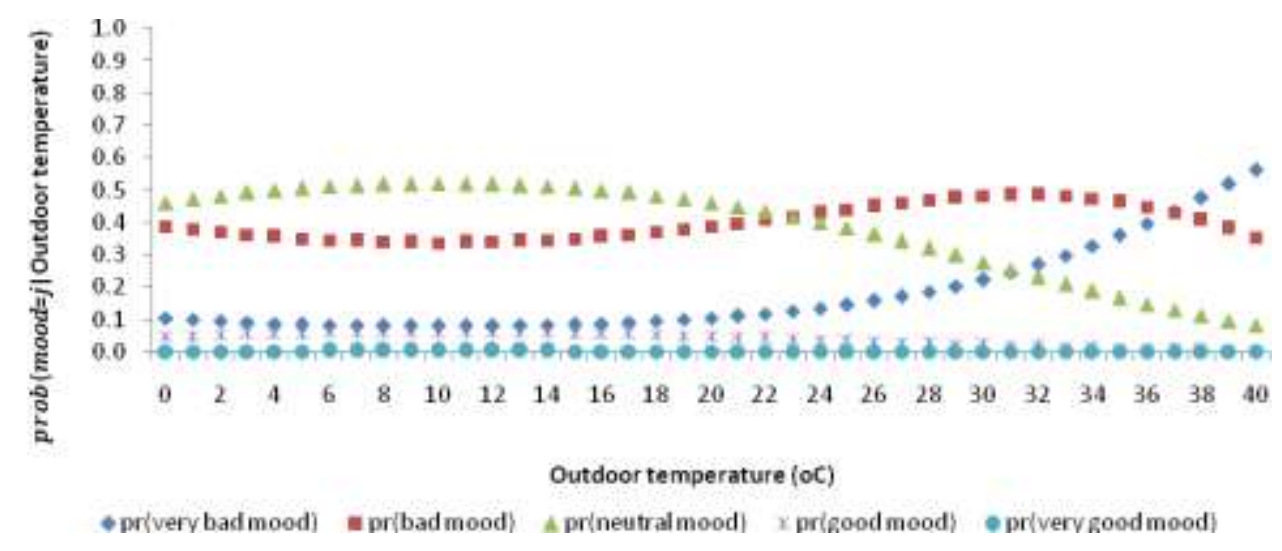

Figure 4. Predicted Probabilities of Different Mood Categories for Different Outdoor Illuminance for a Non-Frail Elderly People with no Dementia Under $7^{\circ}$ c Average Outdoor Temperature

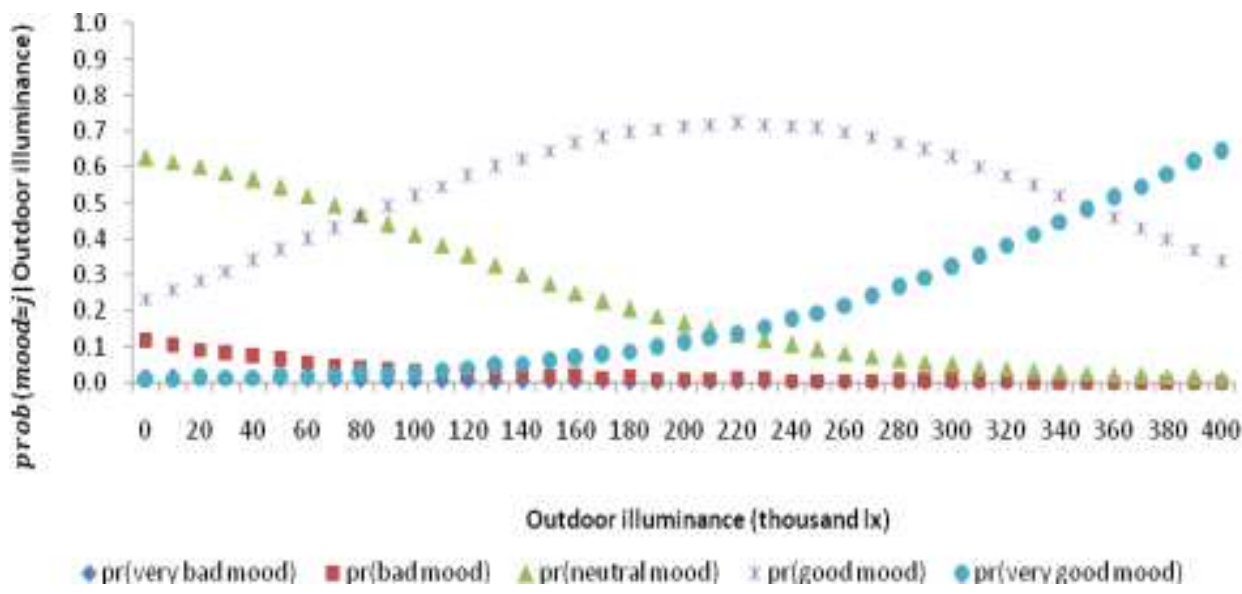

It is evident from Figures 3 and 4 that the probability of happy moods is dominated by higher levels of outdoor illuminance, whereas the probability of sad moods is dominated by higher outdoor temperature levels. It is unrealistic that in daytime when the outdoor temperature is very high $\left(\right.$ e.g. $\left.37^{\circ} \mathrm{C}\right)$, the illuminance level is lower than the average (e.g. 18,500 lux) and/or, when the outdoor illuminance is very high (e.g. 350,000 lux), the temperature level is lower than the average (e.g. $7^{\circ} \mathrm{C}$ ). Therefore, it is unlikely that the elderly 
people's moods on two extreme ends, e.g. very happy and very sad, will be possible to predict under practical outdoor illuminance and temperature levels, except under some hypothetical situations, i.e. 350,000 lux with $7^{\circ} \mathrm{C}$. However, the probability of the mood of an elderly people could shift from one category to other between sad, neutral and happy frequently under real world outdoor environmental conditions, for example, after putting different illumination and temperature values to the model (Equation 1) following has been found: happy mood under 80,000 lux with $10^{\circ} \mathrm{C}$ (non-frail elderly people with no moderate dementia); neutral mood under 18,500 lux with $7^{\circ} \mathrm{C}$ (non-frail elderly people with moderate dementia); and sad mood under 8,000 lux with $-4^{\circ} \mathrm{C}$ (frail elderly people with moderate dementia). It seems that in addition to illumination and temperature physical (i.e. frailness) and psychological conditions (i.e. already depressed/happy due to some news/incidents) might influence shifting one mood to adjacent level under real world outdoor illuminance and temperature levels. For example, frailness can shift the happy mood to a neutral mood under the same 80,000 lux outdoor illumination with $10^{\circ} \mathrm{C}$ outdoor temperature when the elderly people do not suffer from moderate dementia, and if he/she suffers no frailness but moderate dementia the probability of a neutral mood is higher than the probability of a sad mood under the same 8,000 lux outdoor illumination with $-4^{\circ} \mathrm{C}$ outdoor temperature, mentioned above. There might be many other variables that often affect elderly people's moods to switch between different categories, as well, which is not identified in the presented models. Many of the outdoor situations described here for the probabilities of different moods are hypothetical in nature; however, the results convey the message that there might be a strong correlation between outdoor environment and occupants' moods, who lives inside buildings with a sense of outdoor climatic condition. The analysis of this paper also emphasise that under practical outdoor conditions, the probability of bad mood or very bad mood is rare, emphasise the positive effect of the individual's contact with outdoor environment and/or nature.

\section{Limitations}

In this research an attempt is made to estimate the elderly people's moods with the change of outdoor illuminance and temperature. Since, mood is both a sensory and emotional experience, the relationship between outdoor ambient illuminance levels and elderly people's moods in a care home are complex. Psychological factors can have powerful influences on the subjective mood of the occupants, and a number of other factors might affect elderly people's mood and nonverbal expressions, e.g. occupant's background and a particular incident on that day. These types of factors were not considered in the model due to limited access to the occupants, unavailability of information and time.

One of the disadvantages of using the particular care home as a case study is that the total number of occupants in the care home are quite low, only 17 elderly people; therefore, there were less demographic variations in the sample. The findings in this research should not be generally applicable to all age 
groups, as light sensitivity are decreased to the elderly peoples compared to young adults and the effect of light exposure is considered different for elderly people (Van Someren et al. 2002, Campbell et al. 1988). For example, lack of exposure to natural light creates increased sleep disturbances in the aged people compared to young adults (Mishima et al. 2001).

The output of this research is highly sensitive to the staff judgments of residents' moods. The measurement of the elderly peoples' mood was not made by the elderly people themselves as some cases they have limited abilities to express their real mood verbally that could be reliable, in some other cases they feel reluctant to report; therefore, the measurement was made indirectly by a senior member of the care staff after discussion with the care staff who were actually looking after the elderly people. Since, individuals are subject to natural human error, there are possibilities that in some cases stuff might misunderstand and/or misinterpret the occupants' feelings, and there were little scope for further validation of the judgments.

Errors in manual recording of the data are quite common, which is also difficult to identify latter. To add flexibility, this judgemental part of the research was kept in less stringent format; however, the quantitative analysis with collected data that transformed to quantifiable response modes with reasonably sensible, consistent outcome confirms the suitability of the approach followed in this pilot study and, therefore, could be continued for the whole study period designed for one year.

There was little interactions between the researchers and staff during the pilot study period to avoid the influence of authors (with daylight research background) personal opinions during conversations and might bias the staff to rate occupants' moods. Someone might question about the credibility of the staff: the common criticism of qualitative (human involved research) research. The researchers are not allowed to pay for the additional time spent by the stuff to rate and record occupants' moods on the weekly chart due to care home policy, and staff did all the work for this research voluntary; the authors have to satisfy with staff credibility under natural setting, and above mentioned limitations.

To investigate the impact of outdoor illuminance on the change of occupants' moods, in this study, the concept of "ordered" model is retained and the selected model is an OLOGIT model. The other suitable model for an ordered categorical variable is the orderedprobit (OPROBIT) model. The OLOGIT model assumes that the disturbances are Weibull distributed (Gumbel extreme value Type I), whereas the OPROBIT model assumes that the disturbances are multivariate normally distributed. Both formulations, however, provide very similar results (Long 1997) and the OLOGIT model is preferred to the OPROBIT (Quddus et al. 2010). One of the weaknesses of the model presented in this paper is that the model explains only $3.4 \%$ of the proportion of variation by considering outdoor illuminance, temperature, moderate dementia and frailness. The proportion of variation being explained by the model is increased (about 9\%) when more explanatory variables are added to the right hand side of the model (e.g. age, gender, blindness, vascular dementia and advanced dementia). But, inclusion of 
these variables results violation of proportional odds assumption as the p-value (sig) for the general model becomes less than 0.001 , and one set of coefficients for all the categories becomes inappropriate.

The parallel line test for the final model shows an acceptable p-value $(0.150)$ (Chan 2005); however, the value could be changed by including a larger sample size and number of independent variables in the right hand side of the model or reducing the number of mood categories. Variables, such as age and gender might of interest to some studies, therefore, another option to keep these variables in the model would be to identify the specific variables which does not meet the proportional odds assumption in the primary model at the beginning, and use some extensions of OLOGIT model, such as generalized ordered logit (GOLOGIT) or partially constrained generalized ordered logit (PC-GOLOGIT) models, which does not impose the constraints of parallel regressions (Fu 1998). The developed model presented in this paper is still to some extent hypothetical in nature rather practical. Careful attention to data collection with trained people might help to establish more reliable outcome.

\section{Conclusions}

This research examines whether there is any association between the change of elderly people's moods and the level of outdoor illuminance employing ordered response models (ORMs). The analysis shows, assuming all other explanatory variables remain constant, the probability of a better mood increases with the increase of outdoor illuminance. However, it is also evident from the model that in a very hot/cold day probability of a better mood could be decreased under the same outdoor illuminance. Physical and psychological conditions (i.e. frailness and moderate dementia) might influence shifting one mood to the next close one under the same outdoor illuminance and temperature. Future research is needed to replicate these findings.

There are a number of ways to extend the analysis used in this study. It is important to identify all variables that might affect elderly people's moods and to determine the other related attributes of light except intensity (for example, correlated colour temperature) that might impact on individuals' moods.

It would be interesting to analyse impact of morning light, afternoon light and evening light on elderly people's moods separately as there is clear difference in the spectrum (colours) of these lights. For example, daylight is warm at dawn; bright with a bluish cast at midday and rosy at dusk. Another possible extension would be to develop a model based on indoor light levels to explore the association between indoor illuminance and elderly people's moods and to suggest lighting standards for elderly people livings. In such an analysis, the effects of indoor illuminance on different age group and gender could be estimated by including a large number of samples from different care homes and elderly people sheltered accommodations. 


\section{Acknowledgments}

We would like to thank all of the people who helped make the data collection of this research possible. We want to express deep appreciation to Mr Albert Skubala and Mrs Jacqueline Skubala, Owner, Alexandra House, Huncote, Leicester, for extending their kind consent on conducting the study in the Care Home, and for giving time and support for data collection. Mrs Alexandra Shilcock, Manager, Alexandra House, for supplying all relevant information about care home staff and occupants. Mr Konrad Skubala and Mrs Joe Skubala, Maintenance, for their cooperation at different times. Care Staff Hayley Carey, Emma Knight, Sam Hodges, Gina Duncan, Sian Holling, Emma Langford, April Lane, Alison Jespersen, Kamljit Dhillon, Rhiannon Ainge, Anna King, Sophie Draycott, Julie Wilson and Sarah Marsden, who recorded data. Finally, we are most grateful to all occupants of the care home who agreed to be a part of this study. The research reported in this paper was funded by a Loughborough University EPSRC IMCRC (EP/E002323/1) and EPSRC HaCIRIC (Health and Care Infrastructure Research and Innovation Centre) core grants (EP/D039614/1 and EP/I029788/1), UK.

\section{References}

Baron RA, Rea MS, Daniels SG (1992) Effects of indoor lighting (illuminance and spectral distribution) on the performance of cognitive tasks and interpersonal behaviours: the potential mediating role of positive affect. Motivation and Emotion 16(1): 1-33.

Beauchemin KM, Hays P (1996) Sunny hospital rooms expedite recovery from severe and refractory depressions. Journal of Affective Disorders 40(1): 49-51.

Belcher MC, Kluczny R (1987) The effects of light on decision making some experimental results. Proceedings of the Twenty First Session of the Commission Internationale d'\& Eacute. Venice: Clairage.

Benedetti F, Colombo C, Barbini B, Campori E, Smeraldi E (2001) Morning sunlight reduces length of hospitalization in bipolar depression. Journal of Affective Disorders 62(3): 221-223.

Boyce PR, Cuttle C (1990) Effect of correlated colour temperature on the prescription of interiors and colour discrimination performance. Lighting Research and Technology 22(1): 19-36.

Brunswik E (1939) The conceptual focus of some psychological systems. Journal of Unified Science (Erkenntnis) 8 (1939): 36-49.

Brunswik E (1952) The conceptual framework of psychology. International Encyclopedia of Unified Science 1(10). Chicago: The University of Chicago Press.

Brunswik E (1934) Perception and the world of objects: The foundations of a psychology in terms of objects. Leipzig und Wien: F. Deuticke (Post-doctoral thesis).

Campbell SS, Kripke DF, Gillin JC, Hrubovcak JC (1988) Exposure to light in healthy elderly subjects and Alzheimer's patients. Physiology \& Behavior 42(2): 141-4.

CDO (2012) Climate: Leicester. Climate Data for Cities Worldwide. ClimateData.org. June 30, 2016. Retrieved from http://goo.gl/eAqVSZ. 
Chan YH (2005) Biostatistics 305. Multinomial logistic regression. Basic Statistics for Doctors. Singapore Medical Journal 46(6): 259-269.

Cheney CS (2004) The hydrogeology of the Leicester district (geological sheet 156). Groundwater Systems and Water Quality Programme. British Geological Survey, Internal Report, IR/04/085: 19.

Chin HC, Quddus MA (2003) Applying the random effect negative binomial model to examine traffic accident occurrence at signalized intersection. Accident Analysis and Prevention 35(2): 253-259.

Choi JH, Beltran L, Kim H (2012) Impacts of indoor daylight environments on patient average length of stay (ALOS) in a healthcare facility. Building and Environment 50 (April 2012): 65-75. DOI:10.1016/j.buildenv.2011.10.010

Clogg CC, Shihadeh ES (1994) Statistical models for ordinal variables. SAGE series on advanced quantitative techniques Vol. 4. California: Sage Publications.

Dumont M, Beaulieu C (2007) Light exposure in the natural environment: Relevance to mood and sleep disorders. Sleep Medicine 8(6): 557-65.

Edwards L, Torcellini P (2002) A Literature Review of the Effects of Natural Light on Building Occupants. Technical Report, National Renewable Energy Laboratory, U.S. Department of Energy, Golden, Colorado, US.

Fadaizadeh L, Emami H, Samii K (2009) Comparison of Visual Analogue Scale and Faces Rating Scale in Measuring Acute Postoperative Pain. Archives of Iranian Medicine 12(1): 73-5.

Ferrell BA, Ferrell BR, Rivera L (1995) Pain in cognitively impaired nursing home patients. Journal of Pain and Symptom Management 10(8): 591-598.

$\mathrm{Fu} V$ (1998) SG88: Estimating generalized ordered logit models. Stata Technical Bulletin 44: 27-30. Reprinted in Stata Technical Bulletin Reprints 8: 160-164. College Station, TX: Stata Press.

Greene WH (2000) Econometric analysis (4th edn.). Upper Saddle River, New Jersey: Prentice-Hall.

Gujarati D (2003) Basic econometrics (4th edn.). New York: McGraw-Hill.

Hirsh AT, George SZ, Robinson ME (2009) Pain assessment and treatment disparities: a Virtual Human technology investigation. PAIN 143(1-2): 106-113.

Hirsh AT, George SZ, Robinson ME (2011) Patient demographic characteristics and facial expressions influence nurses' assessment of mood in the context of pain: A Virtual Human and lens model investigation. International Journal of Nursing Studies 48(11): 1330-1338.

Holick MF (2004) Sunlight and vitamin D for bone health and prevention of autoimmune diseases, cancers, and cardiovascular disease. American Journal of Clinical Nutrition 80(6): 1678-1688.

Joarder MAR (2011) Incorporation of Therapeutic Effect of Daylight in the Architectural Design of In-patient Rooms to Reduce Patient Length of Stay (LoS) in Hospitals. PhD thesis, School of Civil and Building Engineering, Loughborough University, UK.

Joarder MAR, Price ADF (2013) Impact of daylight illumination on reducing patient length of stay in hospital after coronary artery bypass graft surgery. Lighting Research \& Technology 45(3): 435-449.

Joarder MAR, Price ADF, Mourshed MM (2010) Access to Daylight and Outdoor Views: A comparative study for therapeutic daylighting design. World Health Design 3(1): 62-69.

Kasper S, Wehr TA, Bartko JJ, Gaist PA, Rosenthal NE (1989). Epidemiological findings of seasonal changes in mood and behavior. Archives of General Psychiatry 46(9): 823-833. 
Kecskes I, Rihmer Z, Kiss K, Vargha A, Szili I, Rihmer A (2003) Possible effect of gender and season on the length of hospitalisation in unipolar major depressives. Journal of Affective Disorders 73(3): 279-282.

Kremer E, Atkinson JH, Ignelzi RJ (1981) Measurement of pain: patient preference does not confound pain measurement. PAIN 10(2): 241-248.

Kuller R, Wetterberg L (1993) Melatonin, cortisol, EEG, ECG and subjective comfort in healthy humans: impact of two fluorescent lamps types at two light intensities. Lighting Research and Technology 25(2): 71-81.

Lim HS, Choudhuri R, Peto J, Schwartz G, Baade P, Mcaller H (2006) Cancer survival is dependent on season of diagnosis and sunlight exposure. International Journal of Cancer 119(7): 1530-1536.

Littlefair P (2010) Review of daylighting and windows in homes and applicability to homes of people with sight loss. Research findings number 30, March, Thomas Pocklington Trust, London.

Ljubičić Đ, Stipčević T, Pivac N, Jakovljević M, Mück-Šeler D (2007) The influence of daylight exposure on platelet 5-HT levels in patients with major depression and schizophrenia. Journal of Photochemistry and Photobiology 89(2-3): 63-69.

Lockley SW, Gooley JJ (2006) Circadian photoreception: Spotlight on the brain. Current Biology 46(18): 795-797.

Lomas KJ, Kane T (2013) Summertime temperatures and thermal comfort in UK homes. Building Research and Information 41(3): 259-280.

Long JS (1997) Regression models for categorical and limited dependent variables. California: Sage Publications.

McCloughan CLB, Aspinall PA, Webb RS (1999) The impact of lighting on mood. Lighting Research and Technology 31(3): 81-88.

McCullagh P, Nelder JA (1989) Generalized linear models. London: Chapman and Hall.

Mishima K, Okawa M, Shimizu T, Hishikawa Y (2001) Diminished melatonin secretion in the elderly caused by insufficient environmental illumination. Journal of Clinical Endocrinology and Metabolism 86(1): 129-134.

Nelson TM, Nillson TH, Johnson M (1984) Interaction of temperature, illuminance and apparent time on sedentary work fatigue. Ergonomics 27(1): 89-101.

Nikolopoulou M, Lykoudis S (2006) Thermal comfort in outdoor urban spaces: Analysis across different European countries. Building and Environment 41(11): $1455-1470$.

Norušis MJ (2010) Ordinal Regression. Chapter 4. In PASW Statistics 18 Advanced Statistical Procedures Companion, pp. 69-89. New Jersey: Prentice Hall.

Oren DA, Wisner KL, Spinelli M, Epperson CN, Peindl KS, Terman JS, Terman M (2002) An open trial of morning light therapy for treatment of antepartum depression. The American Journal of Psychiatry 159(4): 666-669.

Quddus MA, Wang C, Ison SG (2010) Road Traffic Congestion and Crash Severity: Econometric Analysis Using Ordered Response Models. Journal of Transportation Engineering 136(5): 424-435.

Revill SI, Robinson JO, Rosen M (1976) The reliability of a linear analog for evaluating pain. Anesthesia 31(9): 1191-1198.

Rosenthal NE, Sack DA, Gillin JC, Lewy AJ, Goodwin FK, Davenport Y, Mueller PS, Newsome DA, Wehr TA (1984) Seasonal affective disorder-a description of the syndrome and preliminary findings with light therapy, Archives of General Psychiatry 41(1): 72-80.

Russell JA, Snodgrass J (1987) Emotion and the environment. Handbook of Environmental Psychology. New York: Wiley. 
Van Someren EJW, Riemersma RF, Swaab DF (2002) Functional plasticity of the circadian system in old age: light exposure. Progress in Brain Research 138 (2002): 205-231. DOI: 10.1016/S0079-6123(02)38080-4.

Walch JM, Rabin BS, Day R, Williams JN, Choi K, Kang JD (2005) The effect of sunlight on postoperative analgesic medication usage: A prospective study of spinal surgery patients. Psychosomatic Medicine 67(1): 156-163.

Whyte MP, Thakker RV (2005) Rickets and osteomalacia. Medicine 33(12): 70-74. 
